

\title{
Influence of gender, age, shelf-life, and conservation method on the biomechanical behavior of colon tissue under dynamic solicitation
}

Damien Massalou, Catherine Masson, Sanae Afquir, Patrick Baque, Pierre Jean Arnoux, Thierry Bege

\section{To cite this version:}

Damien Massalou, Catherine Masson, Sanae Afquir, Patrick Baque, Pierre Jean Arnoux, et al.. Influence of gender, age, shelf-life, and conservation method on the biomechanical behavior of colon tissue under dynamic solicitation. Clinical Biomechanics, 2019, 65, pp.34-40. 10.1016/j.clinbiomech.2019.03.017 . hal-02867999

\section{HAL Id: hal-02867999 \\ https://hal-amu.archives-ouvertes.fr/hal-02867999}

Submitted on 10 Jun 2021

HAL is a multi-disciplinary open access archive for the deposit and dissemination of scientific research documents, whether they are published or not. The documents may come from teaching and research institutions in France or abroad, or from public or private research centers.
L'archive ouverte pluridisciplinaire HAL, est destinée au dépôt et à la diffusion de documents scientifiques de niveau recherche, publiés ou non, émanant des établissements d'enseignement et de recherche français ou étrangers, des laboratoires publics ou privés. 
1 Influence of gender, age, shelf-life, and conservation method on the 2 biomechanical behavior of colon tissue under dynamic solicitation

3 D. Massalou MD PhD* £†, C. Masson $\mathrm{PhD} \dagger, \mathrm{S}$. Afquir $\dagger, \mathrm{P}$. Baqué MD PhD $£, \mathrm{P}-\mathrm{J}$ Arnoux $4 \mathrm{PhD} \dagger, \mathrm{T}$. Bège $\mathrm{MD} \mathrm{PhD} \neq \dagger$

5

$6 £$ Emergency surgery unit, University Hospital of Nice, CHU de Nice Hôpital Pasteur 2,

$7 \quad$ Université de Nice Sophia-Antipolis, France

$8 †$ Biomechanical Applied Laboratory, UMRT24, IFSTTAR, Aix-Marseille University, France

$9 \ddagger$ Department of Visceral Surgery, AP-HM Hôpital Nord, Aix-Marseille University, France

*Corresponding author

Dr Damien MASSALOU

Tel: +33663269264 and +33492038614

Fax: +33492033390

Email: damienmassalou@gmail.com

ORCID: 0000-0002-2015-1661

Dr Catherine Masson

Sanae Afquir

Pr Patrick Baqué

Dr Pierre-Jean Arnoux

Dr Thierry Bège
Catherine.masson@ifsttar.fr sanae.afquir@gmail.com baque.p@chu-nice.fr pierre-jean.arnoux@ifsttar.fr thierry.bege@ap-hm.fr

We have no conflict of interest. 
1 Abstract

2 Background: Data from biomechanical tissue sample studies of the human digestive tract are

3 highly variable. The aim of this study was to investigate 4 factors which could modify the

4 mechanical response of human colonic specimens placed under dynamic solicitation until

5 tissue rupture: gender, age, shelf-life and conservation method.

6 Methods: We performed uniaxial dynamic tests of human colonic specimens. Specimens 7 were taken according to three different protocols: refrigerated cadavers without embalming,

8 embalmed cadavers and fresh colonic tissue. A total of 143 specimens were subjected to

9 tensile tests, at a speed of $1 \mathrm{~m} \mathrm{~s}^{-1}$.

10 Findings: Young's modulus of the different conservation protocols are as follows: embalmed,

$113.08+/-1.99$; fresh, $2.97+/-2.59$; and refrigerated $3.17+/-2.05$. The type of conservation

12 does not modify the stiffness of the tissue $(p=0.26)$ but does modify the stress necessary for

13 rupture $(\mathrm{p}<0.001)$ and the strain required to obtain lesions of the outer layer and the inner 14 layer ( $\mathrm{p}<0.001$ and $\mathrm{p}<0.05$, respectively). Gender is also a factor responsible for a change 15 in the mechanical response of the colon. The age of the subjects and the shelf-life of the 16 bodies did not represent factors influencing the mechanical behavior of the colon $(\mathrm{p}>0.05)$.

17 Interpretation: The mechanical response of the colon tissue showed a biphasic injury 18 process depending on gender and method of preservation. The age and shelf-life of 19 anatomical subjects do not alter the mechanical response of the colon.

21 Abstract word count: 235 words

22 Keywords: colonic mechanical response, human colon, biomechanics, dynamic solicitation 


\section{Introduction}

2 The digestive tract is injured in $3 \%$ of blunt abdominal trauma [1], which mainly occurs in

3 high velocity road accidents. Virtual simulation including biomechanical data reproducing the

4 conditions of trauma allows for the introduction of effective means of prevention [2]. small intestine and the colon, the latter accounting for 30\% of all digestive tract lesions [3], [4]. Traumatic rupture of the colon can lead to serious consequences, with a high risk of complications, including peritonitis due to bowel perforation which can be lethal.

Due to their potential seriousness, these lesions have been studied in biomechanics in order to understand the mechanism of injury. These mechanisms are complex and can simultaneously involve compression, deceleration, and bursting phenomena.

Since the historical works of Yamada [5] and Fung [6], several publications have investigated the mechanical properties of the colon using tensile tests, that replicate the lesional phenomena observed in gastrointestinal-tract trauma. Egorov determined the biomechanical properties from static uniaxial traction tests in humans, and highlighted that the different layers of the bowel wall defines its mechanical strength [7]. From static uniaxial tests on pig intestinal tissue, Carniel [8] showed the anisotropic and non-linear behavior of colonic tissue.

In a previous study, we highlighted the influence of the location on the colon frame on its mechanical response under uniaxial traction, until rupture [9]. This result was also shown in Howes' dynamic bi-axial colon stress [10].

The data on the mechanical behavior presented in these publications show great variability. The heterogeneity of the experimental protocols can explain these differences; the

24 mechanical properties can be modified by the type of solicitation, animal or human model, conservation method (fresh, refrigerated or embalmed), and anthropometric factors (such as 
1 sex, age, and obesity of the subjects studied). Nevertheless, it is important to know the

2 influence of each factor on the mechanical behavior, especially for the development of 3 personalized digital models.

4 Our objective was to determine the influences of four parameters (gender, age, shelf5 life, and conservation method) on the mechanical behavior of the human colon under dynamic 6 solicitation.

8 Materials and Methods

9 Origin of the tissue

10 The colon samples used were generated from three different protocols. The first protocol 11 defined the "fresh" group. Colon samples were taken from people in a state of encephalic 12 death; sub-total colectomy was performed by a visceral surgeon at the end of a multi-organ 13 harvest for organ transplantation. The shelf-life was of 0 days. The use of fresh tissue was 14 incorporated as part of the protocol approved by l'Agence de la Biomédecine et 15 l'Etablissement Français des Greffes of the Marseille university hospital.

16 The second and third protocols used cadaveric human tissue after approval by the ethics 17 committees of the medical schools of Nice and Marseille, with accordance to the donation of 18 bodies for science. The shelf-life of the bodies was systematically recorded.

19 Samples generated from the second protocol is referred to as the "embalmed" group: patients 20 were transferred after their death to the embalming laboratory. The subjects were embalmed 21 with Winkler's liquid [11] then kept at $4^{\circ} \mathrm{C}$ until the colon was removed.

22 The third protocol is referred as the "refrigerated" group. Patients were transferred after their 23 death to the anatomy laboratory and then stored at $1{ }^{\circ} \mathrm{C}$ without preservatives.

24 All tests were carried out at room temperature.

25 The study included only adult subjects whose colon showed no sign of pathology (cancer, 
1 chronic inflammation). Colonic diverticulosis was not a cause of exclusion given its high

2 prevalence in the adult human population. However, none of the colonic specimens harbored 3 diverticula.

\section{Population studied}

6 Eighteen subjects ( 6 men and 12 women) were studied. The "fresh" protocol included one 7 man and three women, with a mean age of 40 years (range: 20-53 years). The "embalmed" 8 protocol consisted of one man and three women, with a mean age of 89 years (range: 82-93

9 years) and mean shelf-life of 42 days. The "refrigerated" protocol included four men and six 10 women, with a mean age of 86 years (range: 73-100 years) and a mean shelf-life of 19 days.

\section{Preparation of the specimens}

13 The specimens were colon segments taken from the antimesenteric side after performing a 14 longitudinal opening with a standardized rectangular punch of the following dimensions: $25 \times$ $15100 \mathrm{~mm}$.

16 For each anatomical subject, eight longitudinal specimens were taken from all segments of the 17 colon: ascending, transverse, descending, and sigmoid colon. The samples were taken in the 18 middle of each segment. The tests were performed on 32 fresh specimens, 32 embalmed 19 specimens, and 80 refrigerated specimens.

Experimental conditions

22 The samples were stored between wet compresses of isotonic saline solution to prevent 23 desiccation. The tests were conducted at room temperature within $24 \mathrm{~h}$ after collection. 24 Hygrometric readings were not performed. Experimental characterization of the mechanical 25 behavior of the colon was carried out by performing uniaxial tensile tests under a dynamic 
1 load of $1 \mathrm{~m} \mathrm{~s}^{-1}$. The modalities of the traction protocol and preconditioning have been detailed

2 previously by our team [9].

Data acquisition and post-processing of results

6 Data were not filtered. The strain-strength curves were zeroed (a $2 \mathrm{~N}$ reset was applied) to

7 remove a possible initial load in the set-up of the samples. Young's modulus was calculated

8 from the linear region during the elastic phase of the stress-strain curves.

All tests were filmed by two VITCam® digital cameras with a recording rate of 1000 frames per second: a camera for the anterior surface of the sample and a second for the

11 posterior surface (figure 1 ). The definition of the image was $1260 \times 960$. The location of the 12 initial damage, the type of damage, the number of lacerations, and damage propagation were 13 analyzed using the video recordings.

Statistical analysis

Statistics were performed using SPSS for Windows version 11.0 (SPSS Inc., Chicago, IL). Regarding film analysis, the non-parametric Mann-Whitney test and Kruskal-Wallis were performed for univariate analysis.

For the statistical analysis of the mechanical behavior, the number of specimens was different depending on the subject. Therefore, to have the same number of samples per

21 subject, we chose to create a weighting variable based on the number of test specimens per 22 individual.

23 To avoid any variability of the results between groups, related to a difference of 24 distribution of the samples on the colon frame, we carried out an ANOVA test to verify that 25 the distribution of samples by subject allowed for a statistical analysis independent of 26 location. 
To explain the influence of each of the explanatory variables, univariate analyzes

2 (ANOVA) were performed. The significant variables were then included in multivariate analyzes by multiple linear regression. The results were considered statistically significant if

4 the p-value was $<0.05$.

\section{$6 \quad$ Results}

7 In all, 144 tests were conducted of which 143 were valid (one specimen having slipped out of 8 the vice). The slipped specimen happened at the beginning of the experience and changes to grasping devices avoid other experimental failures. The ANOVA test shows that the data are homogeneous with respect to the location on the colon frame (> F: 0.314).

\section{Mechanical behavior according to conservation method}

High-speed video analysis - For the three groups, the initial damage manifested as a partial failure of the outer layer of the specimen. The damage occurred suddenly and was always located on the serous side. Therefore, the injury process is a progressive laceration of the different layers until complete rupture.

We found the central region to be the more frequent area for the appearance of the first lesion in all specimens. This is particularly pronounced in embalmed and refrigerated specimens (42\% and $43 \%$ of cases) compared to fresh specimens (14\%). There were one to three ruptures per specimen, with no statistically significant difference between the three groups ( $\mathrm{p}$ $21=0.87)$.

Mechanical behavior as a function of the conservation method - The analysis of the stress-strain curves in the three groups shows a global elastic behavior (Figure 2). Young's modulus, as well as the strain and stress values at the point of the first damage and the rupture point, are given in Table 1. The stress and strain levels show a statistically significant 
1 difference with respect to the points of stress, depending on the method of conservation. Only

2 the elastic modulus of the elastic phase is not modified by the conservation method $(\mathrm{p}=0.718$

3 - Table 2).

4 The fresh colon tolerates large deformations, with a deformation at rupture point of $206 \%$

5 against $55 \%$ for the refrigerated colon and $105 \%$ for the embalmed colon.

6 The stress at elasticity limit (first point of damage) is significantly higher for the embalmed

7 colon than for the other two protocols (0.8 vs. $0.4 \mathrm{MPa}, \mathrm{p}<0.001)$.

8 The stress at the rupture point is lower for the refrigerated colon $(0.7 \mathrm{MPa})$ than for the other

9 two protocols $(0.8 \mathrm{MPa})$, however this result is not statistically significant $(\mathrm{p}=0.718)$.

10

\section{Mechanical behavior according to shelf-life}

High-speed video analysis - The impact of shelf-life was assessed for all specimens. The mean retention period of the bodies was of 16 days (range: 0-76 days). We formed two groups of identical size $(\mathrm{N}=9)$ : body conservation for more or less than 16 days. The serosal lesion was most often concentrated in the central region of the specimen. We observed a difference between specimens less than 16-days-old (51.8\% of cases) and specimens over 16days-old (41.2\% of cases); the specimens with the shortest shelf-life tear significantly more often in the core area than specimens with a longer shelf-life $(\mathrm{p}=0.04)$.

Mechanical behavior depending on preservation duration - The behavior of colonic specimens with respect to shelf-life is presented in Figure 3. Statistical analyses of the values of stress and deformation at the points of inflexion reveal a statistically significant difference in fresh specimens, with a deformation rate at point of rupture of $138 \%$ in samples kept for less than 16 days and of $55 \%$ for those kept for more than 16 days (Table 3). Samples taken from subjects retained for more than 16 days tolerate less deformation than subjects kept for less than 16 days $(\mathrm{p}<0.001)$. 
2 High-speed video analysis - For the refrigerated protocol, male- and female-originating 3 samples have the same number of serosal lesions (1.94 for the male and 1.91 for the female, $\mathrm{p}$

$4=0.91$ ). The serosal lesions are mostly concentrated in the central region of the specimens for 5 male (48.4\% of cases) samples, but this trend is reduced in female samples (42.9\% of cases).

6 This difference was not statistically significant $(\mathrm{p}=0.97)$.

7 Mechanical behavior depending on gender - The behavior of colonic specimens according to 8 gender is presented in Figure 4. A statistically significant difference was found between men 9 and women in the behavior of refrigerated specimens for all parameters (Table 4). Young's modulus, stress at first point of damage, and stress at rupture point are higher for the female-

11 than male-originating samples $(\mathrm{p}=0.002, \mathrm{p}<0.001$, and $\mathrm{p}<0.001$, respectively).

The behavior of the colon according to age

High-speed video analysis - The mean age of the subjects in our study is 76-years-old. We divided the subjects into two identical groups $(\mathrm{N}=9)$ : more or less than 76-years-old. The cinematographic analysis of the specimens showed no statistically significant difference related to the age of the individuals $(\mathrm{p}=0.11)$.

Mechanical behavior depending on age - The mechanical behavior of colonic specimens according to age is presented in Figure 5. We found the difference in behavior of fresh specimens to be statistically significant, particularly at rupture, with first deformation point at $66 \%$ for the oldest patients and $186 \%$ for the youngest (Table $5 ; \mathrm{p}=0.03$ for the first inflexion point and $\mathrm{p}<0.001$ for the second inflexion point). 


\section{Relative influence of each factor on the mechanical response of the colon}

$4 \quad$ We analyzed all data acquired during this study without subgroup analysis. The parameters that could explain a change in the recorded mechanical response were analyzed for all subjects. The mean age of subjects was 76 years and the mean retention period was 16 days. Univariate analysis was performed to identify statistically significant factors. The results are shown in Table 6.

A multivariate analysis was then performed using linear regression. Since this is a multiple linear regression, only the first point of inflexion was studied, the second point of

11 inflexion being dependent on the first. The type of profile studied is female, with embalming, of less than 76-years-old, and with a shelf-life less than 16 days. The results are shown in Table 7.

The type of conservation strongly modifies the mechanical response. In the linear regression, the intercept is modified by about $30 \%$ by the type of conservation for the first point of inflexion, the embalmed colon tolerating more deformation than the other types of conservation. Nevertheless, Young's modulus is not modified by the type of conservation. Young's modulus is modified by gender: men have a lower Young's modulus than women by about $30 \%$. The gender also modifies the mechanical stress of the colon.

21 is relatively small. model. 


\section{Discussion}

2 This study on the human colon is a continuation of earlier works, including the studies of

3 Yamada [5], Fung [6], Egorov [7] , and Christensen [12]. The tests revealed a global behavior

4 of specimens with a first linear elastic phase leading to initial damage, followed by a second

5 phase of plastic deformation before complete rupture. Our results show that the colonic

6 mechanical response is ductile and bilayer in dynamic longitudinal tensile loading conditions.

Being a biological tissue, the mechanical behavior could be influenced by the methods

of conservation [12]. Although studies show that in quasi-static tests the differences between

fresh and cadaverous digestive tissue are negligible [7], no work had thus far evaluated

possible differences for the human colon under dynamic stress. This protocol has

11 demonstrated the impact of conservation methods on the mechanical response of this

12 viscoelastic tissue; there is a significant difference in the mechanical response between fresh and preserved tissue, be it by embalming or refrigeration at $1{ }^{\circ} \mathrm{C}$. Specimens from fresh subjects require greater deformation to achieve rupture. These results are consistent with our team's previous work on the small intestine [13] and other teams that have shown that different conservation methods alter the collagen and elastin fiber structure, which further modifies the mechanical response [14],[15],[16].

Several studies confirm the impact of storage temperature as a factor that modifies the mechanical response: freezing at $-10^{\circ} \mathrm{C}$ or $-20^{\circ} \mathrm{C}$ decreases the stress and strain levels required for rupture compared to fresh samples [16],[17],[18]. The use of other preservatives has also been studied, notably salt crystals [19] or vasilated solutions, but these did not alter mechanical response [20]

The temperature of the tests was constant at $22^{\circ} \mathrm{C}$. Some authors perform their tests at

24 body temperature $\left(37^{\circ} \mathrm{C}\right)$. We suspect that the temperature of the tests would not change the 25 mechanical behavior of the specimen, as long as we avoid extreme temperatures [20], [21]. 
1 However, a study on the behavior of a collagen matrix showed a decrease of Young's

2 modulus if the temperature of the test was increased from $23^{\circ} \mathrm{C}$ to $37^{\circ} \mathrm{C}$ [22].

The use of fresh or non-embalmed colon should be preferred. Our sampling was always

4 done with repeated application of saline; drying may be responsible for a change in the

5 mechanical behavior of the tissue [20],[23],[22]. mechanical response. This is in contradiction with Ocala's work [24], which showed an increase in the stiffness of the material with an increase in sample shelf-life. Nevertheless, because the experimental protocols used differ greatly, other factors (e.g., type of tests and the speed of stress) can explain this difference.

In our study, we have demonstrated that the modification of colon mechanical behavior is related to gender, particularly for Young's modulus and stress. Specimens from female subjects require greater strain for lesions. It has already been demonstrated that female gender is an independent predictor of smooth muscle cell stiffening. This pro-rigidity effect represents an important element [25], [26], but does not change with age [27]. Only one publication previously studied the influence of gender on colonic mechanical behavior, using a manometric catheter. These authors detected no significant differences [28]. Our protocol is different from that of Viebig's [28]: we performed dynamic uniaxial tests carried out till rupture, while Viebig performed quasi-static circular measurements of the colon and rectum under physiological conditions.

Regarding the influence of age on the mechanical response of the human colon, our results show a small change in the mechanical response of samples taken from subjects aged 23 over 76 years. Two other studies did not find an association between age and mechanical 24 response, be it for the human vagina [29] or the human colon [19]. Nevertheless, age greater 25 than 65 years has been described as being able to reduce tissue rupture thresholds [15][30]. 
This study has several limitations, amongst which is the low number of specimens

2 tested, particularly for the embalmed and fresh protocol-derived samples. There is a limitation

3 due to the heterogeneity of gender population and the difference between number of

4 specimens according to each conservation method. We did detect an inter-individual

5 variation, but this was considered as not significant in ANOVA. It is, however, difficult to

6 obtain a larger number of samples. Uniaxial studies do not consider the three-dimensional

7 behavior of the digestive tract, but they do allow an accurate study of the behavior of the

8 colonic wall. The influence of loading speed will need to be addressed in order to appreciate

9 the differences of biomechanical behaviors between a colon in a traumatic situation (dynamic

10 tests) and a colon in a physiological or surgical situation (quasi-static tests). Other fields of

11 application seem to benefit from our study, such as the development of computer simulations

12 in the study of road accidents.

\section{Conclusion}

15 We evaluated the mechanical behavior of the colon in a traumatic situation by dynamic 16 traction tests. The dynamic study of the colon under uniaxial traction at $1 \mathrm{~m} \mathrm{~s}^{-1}$ revealed its 17 viscoelastic behavior. There is a change in the mechanical behavior of the colon depending on gender and method of body conservation, whereas the age of the subjects and the shelf-life do not modify it. The use of fresh or non-embalmed human tissue is preferred. Static tests are now needed to complete the mechanical study of the human colon.

\section{$23 \quad$ Funding}

24 This research did not receive any specific grant from funding agencies in the public, 25 commercial, or not-for-profit sectors. 


\section{$2 \quad$ Manuscript editing}

3 Manuscript has been edited by Dr Vaihere Delaune and American Manuscript Editors.

4

5 Conflict of interest

6 All the authors declare they have no conflict of interest

7

8 


\section{References}

2 [1] D. D. Watts and S. M. Fakhry, "Incidence of hollow viscus injury in blunt trauma: an analysis from 275,557 trauma admissions from the East multi-institutional trial," $J$. Trauma, vol. 54, no. 2, pp. 289-294, Feb. 2003.

[2] T. Whyte, T. Gibson, D. Eager, and B. Milthorpe, "Full-face motorcycle helmet protection from facial impacts: an investigation using THOR dummy impacts and SIMon finite element head model," Inj. Prev. J. Int. Soc. Child Adolesc. Inj. Prev., vol. 23, no. 3, pp. 205-210, 2017.

[3] N. A. Nash et al., "Seat Belt Use and its Effect on Abdominal Trauma: A National Trauma Databank Study,” Am. Surg., vol. 82, no. 2, pp. 134-139, Feb. 2016.

[4] M. D. Williams, D. Watts, and S. Fakhry, "Colon injury after blunt abdominal trauma: results of the EAST Multi-Institutional Hollow Viscus Injury Study,” J. Trauma, vol. 55, no. 5, pp. 906-912, Nov. 2003.

[5] H. Yamada, Strength of Biological Materials. Baltimore: Williams \& Wilkins, 1970.

[6] Y.-C. Fung, Biomechanics - Mechanical properties of living tissues, 2nd edition., 1 vols. Springer, 1993.

[7] V. I. Egorov, I. V. Schastlivtsev, E. V. Prut, A. O. Baranov, and R. A. Turusov, "Mechanical properties of the human gastrointestinal tract," J. Biomech., vol. 35, no. 10, pp. 1417-1425, Oct. 2002.

[8] E. L. Carniel et al., "Characterization of the anisotropic mechanical behaviour of colonic tissues: experimental activity and constitutive formulation," Exp. Physiol., vol. 99, no. 5, pp. 759-771, May 2014.

[9] D. Massalou et al., "Dynamic biomechanical characterization of colon tissue according to anatomical factors," J. Biomech., vol. 49, no. 16, pp. 3861-3867, Dec. 2016. 
1 [10] M. K. Howes and W. N. Hardy, "Material properties of the post-mortem colon in highrate equibiaxial elongation," Biomed. Sci. Instrum., vol. 48, pp. 171-178, 2012.

[11] G. Winkler, Manuel d'Anatomie Topographique et Fonctionnelle, 2nd edition. Paris: Masson, 1974.

[12] M. B. Christensen, K. Oberg, and J. C. Wolchok, “Tensile properties of the rectal and sigmoid colon: a comparative analysis of human and porcine tissue," SpringerPlus, vol. 4, Mar. 2015.

[13] S. Bourgouin et al., "Biomechanical characterisation of fresh and cadaverous human small intestine: applications for abdominal trauma," Med. Biol. Eng. Comput., vol. 50, no. 12, pp. 1279-1288, Dec. 2012.

[14] L. Zhou et al., "Biomechanical Properties and Associated Collagen Composition in Vaginal Tissue of Women with Pelvic Organ Prolapse," J. Urol.

[15] A. Brüel and H. Oxlund, "Changes in biomechanical properties, composition of collagen and elastin, and advanced glycation endproducts of the rat aorta in relation to age," Atherosclerosis, vol. 127, no. 2, pp. 155-165, Dec. 1996.

[16] X. Xia, B. Kong, Y. Xiong, and Y. Ren, "Decreased gelling and emulsifying properties of myofibrillar protein from repeatedly frozen-thawed porcine longissimus muscle are due to protein denaturation and susceptibility to aggregation," Meat Sci., vol. 85, no. 3 , pp. 481-486, Jul. 2010.

[17] A. Quirinia and A. Viidik, "Freezing for postmortal storage influences the biomechanical properties of linear skin wounds," J. Biomech., vol. 24, no. 9, pp. 819$823,1991$.

[18] H. Huang, J. Zhang, K. Sun, X. Zhang, and S. Tian, "Effects of repetitive multiple freeze-thaw cycles on the biomechanical properties of human flexor digitorum 
superficialis and flexor pollicis longus tendons," Clin. Biomech., vol. 26, no. 4, pp. 419423, May 2011.

[19] D. A. Watters, A. N. Smith, M. A. Eastwood, K. C. Anderson, R. A. Elton, and J. W. Mugerwa, "Mechanical properties of the colon: comparison of the features of the African and European colon in vitro," Gut, vol. 26, no. 4, pp. 384-392, Apr. 1985.

[20] C. Rubod, M. Boukerrou, M. Brieu, P. Dubois, and M. Cosson, "Biomechanical Properties of Vaginal Tissue. Part 1: New Experimental Protocol," J. Urol., vol. 178, no. 1, pp. 320-325, Jul. 2007.

[21] C. Wex, A. Stoll, M. Fröhlich, S. Arndt, and H. Lippert, "Mechanics of fresh, frozenthawed and heated porcine liver tissue," Int. J. Hyperth. Off. J. Eur. Soc. Hyperthermic Oncol. North Am. Hyperth. Group, vol. 30, no. 4, pp. 271-283, Jun. 2014.

[22] S. Meghezi, F. Couet, P. Chevallier, and D. Mantovani, "Effects of a Pseudophysiological Environment on the Elastic and Viscoelastic Properties of Collagen Gels,” Int. J. Biomater., vol. 2012, pp. 1-9, 2012.

[23] M.-H. Lacoste-Ferré, P. Demont, J. Dandurand, E. Dantras, D. Duran, and C. Lacabanne, "Dynamic mechanical properties of oral mucosa: Comparison with polymeric soft denture liners," J. Mech. Behav. Biomed. Mater., vol. 4, no. 3, pp. 269274, Apr. 2011.

[24] S. Ocal, M. U. Ozcan, I. Basdogan, and C. Basdogan, "Effect of preservation period on the viscoelastic material properties of soft tissues with implications for liver transplantation,” J. Biomech. Eng., vol. 132, no. 10, p. 101007, Oct. 2010.

[25] C. L. Dinardo et al., "Smoking and Female Sex: Independent Predictors of Human Vascular Smooth Muscle Cells Stiffening," PLOS ONE, vol. 10, no. 12, p. e0145062, Dec. 2015. 
1 [26] D. P. Sokolis and D. C. Iliopoulos, "Impaired mechanics and matrix metalloproteinases/inhibitors expression in female ascending thoracic aortic aneurysms," J. Mech. Behav. Biomed. Mater., vol. 34, pp. 154-164, Jun. 2014.

[27] S. J. Vermeersch et al., "Age and gender related patterns in carotid-femoral Pwv and carotid and femoral stiffness in a large healthy, middle-aged population," J. Hypertens., vol. 26, no. 7, pp. 1411-1419, Jul. 2008.

[28] R. G. Viebig, J. F. Pontes, and N. H. Michelsohn, "Electromanometry of the rectosigmoid in colonic diverticulosis," Arq. Gastroenterol., vol. 31, no. 4, pp. 135-144, Dec. 1994.

[29] A. S. Gilchrist, A. Gupta, R. C. Eberhart, and P. E. Zimmern, “Do Biomechanical Properties of Anterior Vaginal Wall Prolapse Tissue Predict Outcome of Surgical Repair?,” J. Urol., vol. 183, no. 3, pp. 1069-1073, Mar. 2010.

[30] W. Koeller, S. Muehlhaus, W. Meier, and F. Hartmann, "Biomechanical properties of human intervertebral discs subjected to axial dynamic compression-Influence of age and degeneration,” J. Biomech., vol. 19, no. 10, pp. 807-816, 1986. 


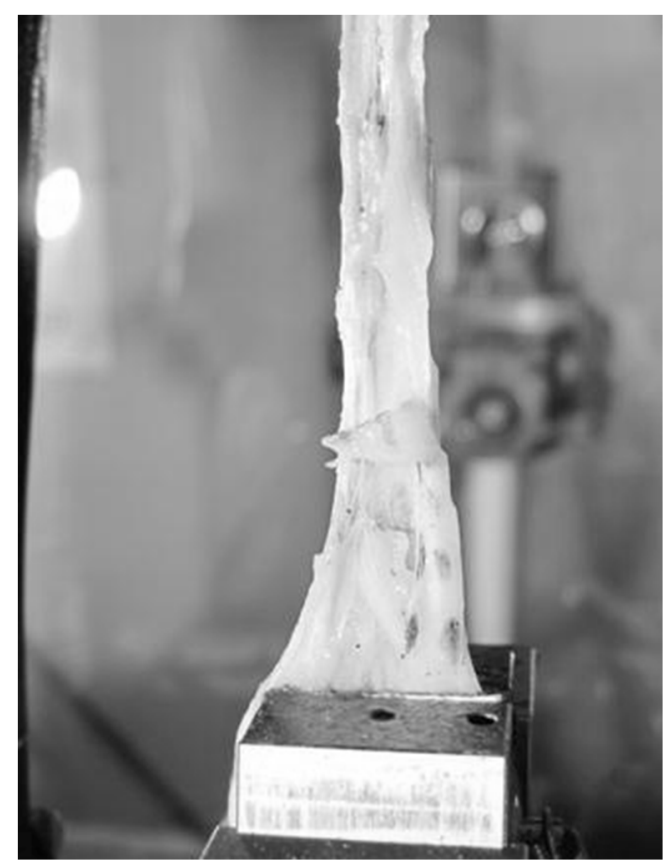

Figure 1: outer layer damage during an uniaxial dynamic tensile load of a human colon. 


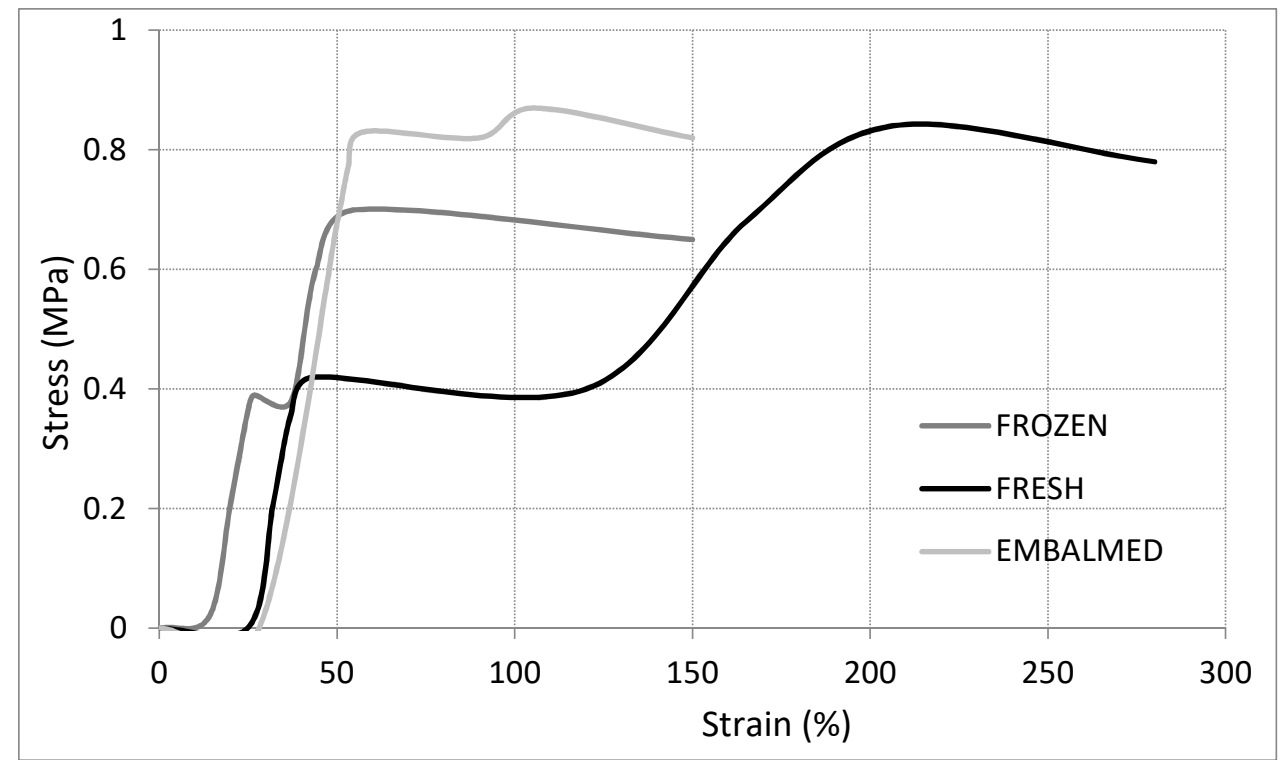

Figure 2: Standard stress- strain curves for longitudinal specimens under dynamic solicitation depending on the method of preservation. The x-axis corresponds to the strain (\%) and the y-axis to the stress (MPa). 


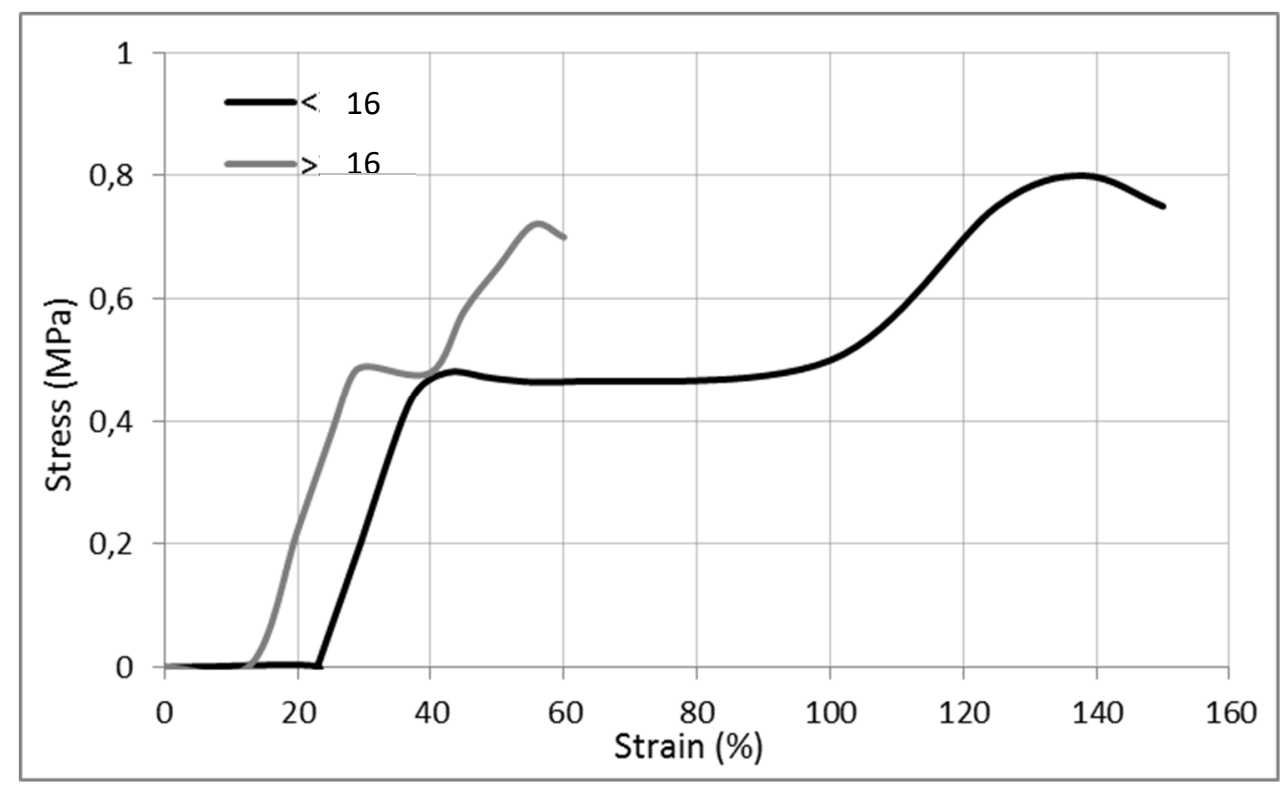

Figure 3: Standard stress-strain curves for longitudinal specimens under dynamic solicitation depending on the duration of preservation. The $\mathrm{x}$-axis corresponds to the strain $(\%)$ and the $\mathrm{y}$ axis to the stress (MPa). $<16$ means that the colon was taken from a subject who died less than sixteen days ago; > 16 means that the colon was taken from a subject who has been dead for more than 16 days. 


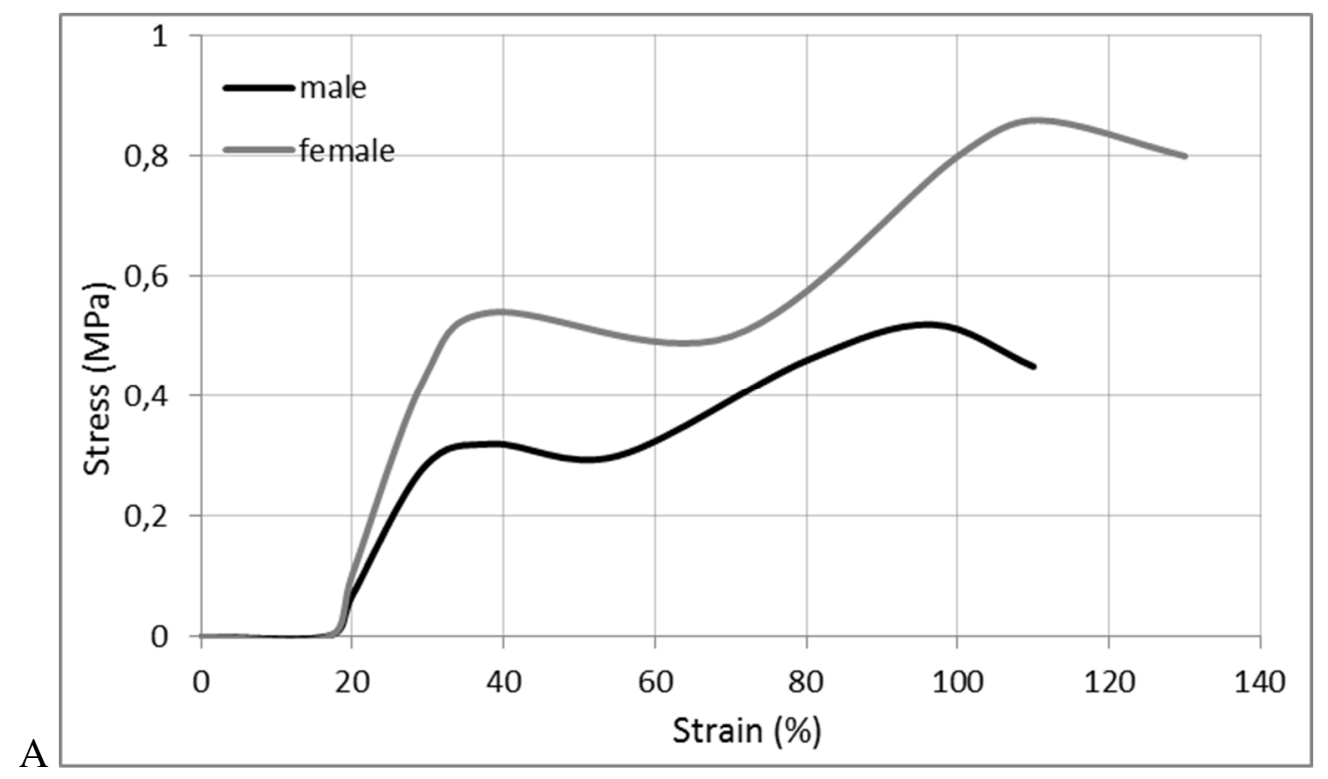

Figure 4: stress-strain curves for longitudinal dynamic specimens depending on the gender. The $\mathrm{x}$-axis corresponds to the strain $(\%)$ and the $\mathrm{y}$-axis corresponds to the stress (MPa). 


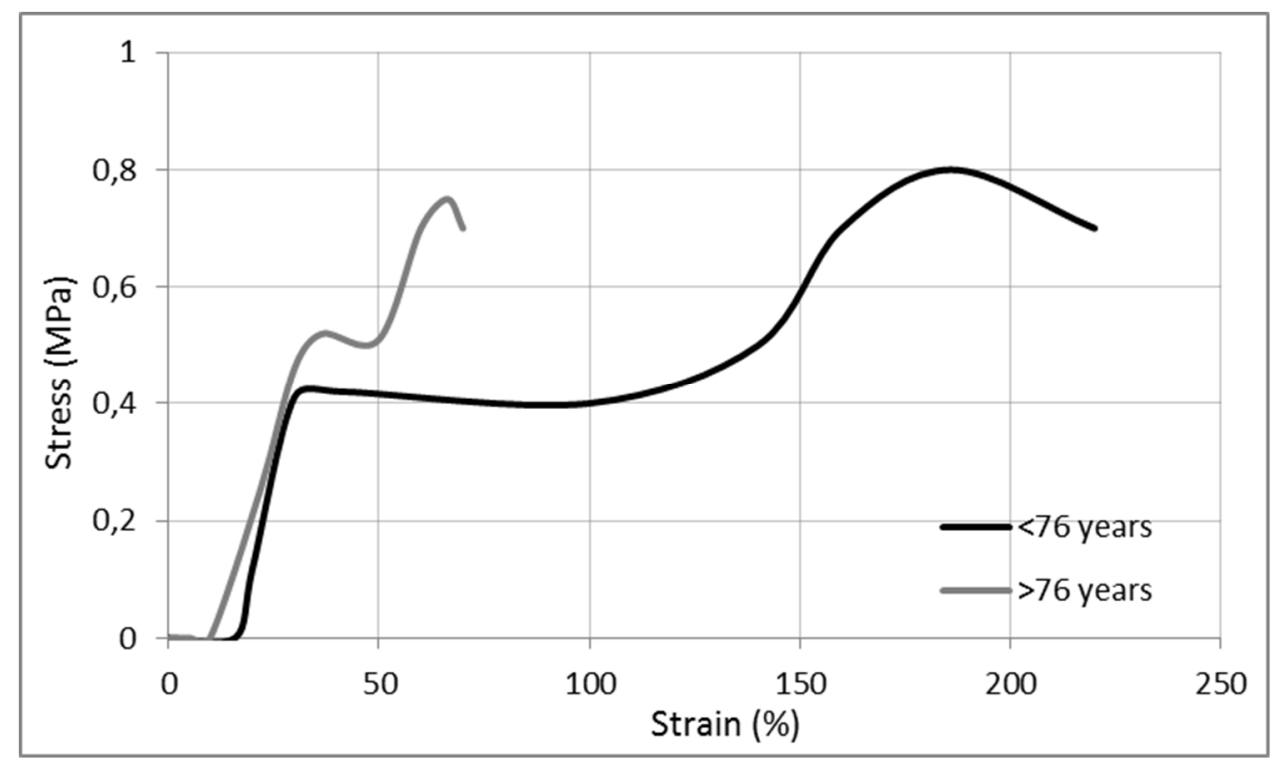

Figure 5: stress-strain curves for longitudinal dynamic specimens depending on the age. The $\mathrm{x}-$ axis corresponds to the strain (\%) and the y-axis corresponds to the stress (MPa). 


\begin{tabular}{ccccc}
\hline Patient & Gender & Age $(\mathbf{y})$ & Protocol & Shelf life(d) \\
\hline $\mathbf{1 2 4 - 1 0}$ & $\mathrm{F}$ & 91 & $\mathrm{E}$ & 76 \\
$\mathbf{1 2 9 - 1 0}$ & $\mathrm{M}$ & 82 & $\mathrm{E}$ & 46 \\
$\mathbf{3 9 - 1 1}$ & $\mathrm{F}$ & 93 & $\mathrm{E}$ & 28 \\
$\mathbf{4 4 - 1 1}$ & $\mathrm{F}$ & 91 & $\mathrm{E}$ & 17 \\
Average & & $89+/-5$ & & $42+/-26$ \\
& & & & \\
SF1 & $\mathrm{M}$ & 20 & $\mathrm{~F}$ & 0 \\
SF2 & $\mathrm{F}$ & 38 & $\mathrm{~F}$ & 0 \\
SF3 & $\mathrm{F}$ & 49 & $\mathrm{~F}$ & 0 \\
SF4 & $\mathrm{F}$ & 53 & $\mathrm{~F}$ & 0 \\
Average & & $40+/-15$ & & - \\
& & & & 21 \\
$\mathbf{1}$ & $\mathrm{F}$ & 100 & $\mathrm{R}$ & 2 \\
$\mathbf{2}$ & $\mathrm{F}$ & 84 & $\mathrm{R}$ & 33 \\
$\mathbf{3}$ & $\mathrm{F}$ & 81 & $\mathrm{R}$ & 34 \\
$\mathbf{4}$ & $\mathrm{M}$ & 84 & $\mathrm{R}$ & 12 \\
$\mathbf{5}$ & $\mathrm{F}$ & 86 & $\mathrm{R}$ & 25 \\
$\mathbf{6}$ & $\mathrm{M}$ & 88 & $\mathrm{R}$ & 23 \\
$\mathbf{7}$ & $\mathrm{M}$ & 73 & $\mathrm{R}$ & 13 \\
$\mathbf{8}$ & $\mathrm{M}$ & 96 & $\mathrm{R}$ & 16 \\
$\mathbf{9}$ & $\mathrm{F}$ & 82 & $\mathrm{R}$ & $19+/-10$ \\
$\mathbf{1 0}$ & $\mathrm{F}$ & 89 & $\mathrm{R}$ & \\
Average & & $86+/-8$ & & \\
\hline & & & & \\
\hline
\end{tabular}

Table 1: Specimen matrix. For gender: $\mathrm{M}$ for male and $\mathrm{F}$ for female. For conservative method: $\mathrm{F}$ for « fresh », E for « embalmed » and R for « refrigerated ». 


\begin{tabular}{lccc}
\hline \hline & Embalmed & Fresh & Refrigerated \\
Modulus of the elastic phase (MPa) & $3.1+/-2$ & $3+/-2.6$ & $32+/-2.1$ \\
Strain at 1st inflexion (\%) & $57.3+/-47.5$ & $43.3+/-29.8$ & $26.7+/-12$ \\
Stress at 1st inflexion (MPa) & $0.8+/-0.4$ & $0.4+/-0.3$ & $0.4+/-0.2$ \\
Strain at 2nd inflexion (\%) & $105.3+/-78.4$ & $206.4+/-135.8$ & $55.4+/-31.7$ \\
Stress at $\mathbf{2 ~}^{\text {nd }}$ inflexion (MPa) & $0.9+/-0.4$ & $0.8+/-0.4$ & $0.7+/-0.3$ \\
\hline \hline
\end{tabular}

Table 2: Influence of method of preservation on the mechanical response of the longitudinal specimen 


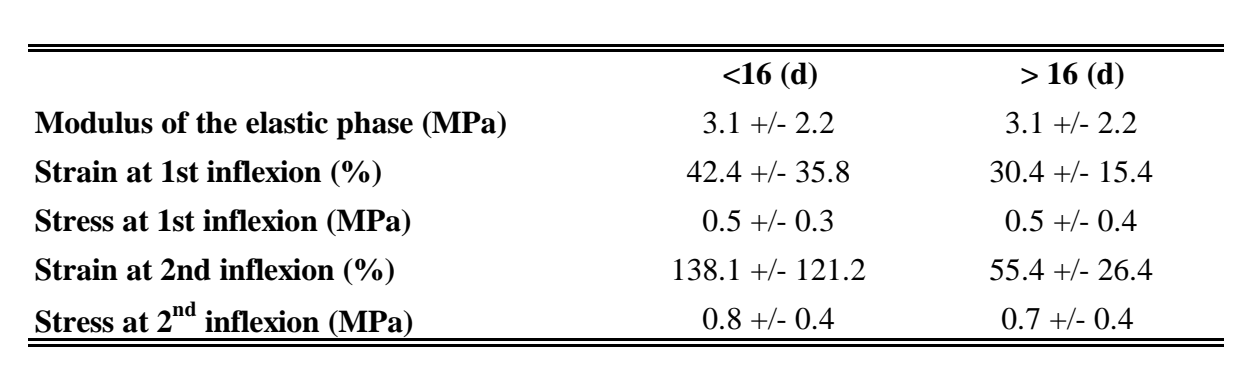

Table 3: Influence of preservation duration on the mechanical response of the refrigerated specimens. $<16$ meanss that the colon was taken from a subject who die 
d less than sixteen days ago; $>16$ means that the colon was taken from a subject who has been dead for less than 16 days $>16$ means that the colon was taken from a subje 
ct who died more than sixteen days ago 


\begin{tabular}{lcc}
\hline \hline & Male & Female \\
Modulus of the elastic phase (MPa) & $2.2+/-2$ & $3.4+/-2.2$ \\
Strain at 1st inflexion (\%) & $38.5+/-24$ & $38.3+/-32.9$ \\
Stress at 1st inflexion (MPa) & $0.3+/-0.2$ & $0.5+/-0.3$ \\
Strain at 2nd inflexion (\%) & $96.5+/-84$ & $110.6+/-111.7$ \\
Stress at 2nd inflexion (MPa) & $0.5+/-0.2$ & $0.9+/-0.4$ \\
\hline
\end{tabular}

Table 4: Influence of gender on the mechanical response of the refrigerated specimens. 


\begin{tabular}{lcc}
\hline \hline & $<\mathbf{7 6}(\mathbf{y})$ & $>\mathbf{7 6}(\mathbf{y})$ \\
Modulus of the elastic phase (MPa) & $2.9+/-2.5$ & $3.2+/-2$ \\
Strain at 1st inflexion (\%) & $41.7+/-28.4$ & $36.5+/-32.2$ \\
Stress at 1st inflexion (MPa) & $0.4+/-0.3$ & $0.5+/-0.3$ \\
Strain at 2nd inflexion (\%) & $185.9+/-134.9$ & $66.3+/-50.3$ \\
Stress at 2n $2^{\text {nd }}$ inflexion (MPa) & $0.8+/-0.4$ & $0.8+/-0.4$ \\
\hline \hline
\end{tabular}

Table 5: Influence of preservation duration on the mechanical response of the refrigerated specimens. $<76$ means that the subject was under the age of $76 ;>76$ 
means that the subject was above the age of 76 


\begin{tabular}{|c|c|c|c|c|}
\hline & Conservative method & Preservation duration & Gender & Age \\
\hline Modulus of the elastic phase (MPa) & 0.718 & 0.356 & 0.002 & 0.146 \\
\hline Strain at 1st inflexion (\%) & $<0.001$ & 0.148 & 0.822 & 0.03 \\
\hline Stress at 1st inflexion (MPa) & $<0.001$ & 0.361 & 0.001 & 0.16 \\
\hline Strain at 2nd inflexion (\%) & $<0.001$ & $<0.001$ & 0.637 & $<0.001$ \\
\hline Stress at $2^{\text {nd }}$ inflexion (MPa) & 0.0919 & 0.431 & $<0.001$ & 0.517 \\
\hline
\end{tabular}

Table 6: univariate analysis

Bold $p$-values are statistically significant and included in multivariate analysis 


\begin{tabular}{|c|c|c|c|c|c|c|c|}
\hline & & Intercept & Preservation method: Fresh & Preservation method: Refrig & Gender: Male & Age & $\mathbf{R}^{2}$ \\
\hline$E(\mathrm{~N} / \mathrm{mm} 2)$ & Gender & 3.4622 & & & -1.219 & & 0.06895 \\
\hline strain 1st point of inflexion (\%) & Preservation method + Age & 131.2044 & -55.5726 & -39.5253 & & -0.7547 & 0.2394 \\
\hline stress 1st point of inflexion (Mpa) & Preservation method + Gender & 0.835 & -0.38013 & -0.3993 & -0.11963 & & 0.2858 \\
\hline
\end{tabular}

Table 7: multivariate analysis - only statistically relevant regressions are presented in this table

Profile: Woman, embalmed type of conservation, $<76$ years, shelf life $<16$ days 